\title{
Dyke-Davidoff-Masson-Syndrome Manifested by seizures and learning difficulties: A Case Report
}

\author{
Khalil MI ${ }^{1}$, Hakim $\mathrm{M}^{2}$, Momin $\mathrm{A}^{3}$, Nayeem A ${ }^{4}$, Islam $\mathrm{MM}^{5}$, Das $\mathrm{PC}^{6}$
}

\begin{abstract}
Dyke-Davidoff-Masson Syndrome (DDMS), also known as cerebral hemiatrophy, is a rare clinical condition characterized by seizures, facial asymmetry, contralateral spastic hemiplegia or hemiparesis, with learning difficulties and behavioral changes. It is commonly diagnosed in presence of clinical feature associated radiological findings which include cerebral hemiatrophy with homolateral hypertrophy of the skull and sinuses. In this present case report a 12 year old teenager female patient was diagnosed as DDMS with recurrent generalized seizures, learning difficulties and right sided hemiparesis. Magnetic resonance imaging (MRI) of the brain showed hemiatrophy involving the left cerebral hemisphere and EEG showed generalized epileptiform discharged. An X-ray of the paranasal air sinuses was normal. [J Shaheed Suhrawardy Med Coll, 2013;5(2):111-113]
\end{abstract}

Keywords: hemiatrophy, seizures, Dyke-Davidoff-Masson-Syndrome, DDMS, learning difficulties

Received: December 2012; Revised: March 2013; Accepted: August 2013

\section{Introduction}

Dyke-Davidoff-Masson Syndrome was first described by C.G. Dyke, L.M. Davidoff and C. B. Masson in 1933 in a series of nine patients with plain skull radiographic and pneumato-encephalographic changes ${ }^{1-2}$. The condition is characterized by facial asymmetry, contralateral hemiplegia or hemiparesis, seizures, mental retardation, and behavioral changes, cerebral hemiatrophy, thickening or thinning of cranial vault ${ }^{3-6}$. The above features may be present in varying combination and degree of severity. Diagnosis is usually achieved by clinical history, examination and radiological investigation. The condition is usually diagnosed in childhood however rare cases of the condition diagnosed in teenagers and young adults have been made. Here a 12 year old female patient who presented to us with seizures, learning difficulties and characteristic radiologic findings suggestive of DDMS.

\section{Case Presentation}

A 12 old female teenager presented with recurrent generalized seizures with developmental delay and learning difficulties since her age three in the department of neurology, at Shaheed Suhrawardy Medical College Hospital, Dhaka. Patient had several episodes of generalized seizure with each episode lasting for approximately 3 to 5 minutes with loss of consciousness with regaining slowly. Patient was a known case of seizure disorder and was not on regular medication. There was no control of seizures even when on medication. Patient was also given some native medicines but with no improvement

1. Dr. Mohammad Ibrahim Khalil, Assistant Professor, Department of Neurology, Shaheed Suhrawardy Medical College, Dhaka

2. Prof. Maliha Hakim, Professor \& Head, Department of Neurology, Shaheed Suhrawardy Medical College, Dhaka

3. Dr. Afzal Momin, Assistant Professor, Department of Clinical Neurology, National Institute of Neurosciences \& Hospital, Dhaka

4. Dr. Abu Nayeem, Assistant Professor, Department of Clinical Neurology, National Institute of Neurosciences \& Hospital, Dhaka

5. Dr. Md. Mohitul Islam, Assistant Professor, Department of Neurology, Shaheed Suhrawardy Medical College Hospital, Dhaka

6. Dr. Priyatosh Chandra Das, Assistant Professor, Department of Neurology, Shaheed Suhrawardy Medical College, Dhaka

\section{Correspondence}

Dr. Mohammad Ibrahim Khalil, Assistant Professor, Department of Neurology, Shaheed Suhrawardy Medical College Hospital (ShSMCH), Sher-EBangla Nagar, Dhaka-1207, Bangladesh; Email: ibrahimbd98@yahoo.com; Cell no.: +8801711898882 
in symptoms. Despite all the above efforts she was getting seizures irregularly. Patient's birth history was uneventful. However, patient's developmental history was significant with delayed milestones and mental retardation. Patient has not done any schooling so far. No history of any serious childhood infections like fever or trauma could be elicited. On examination, patient was a teenager girl moderately built and nourished. The patient was mild disoriented to time, place and person with irrelevant talking. The general physical examination was normal. Neurological examination revealed facial asymmetry, right sided spastic hemiparesis with brisk deep tendon reflexes and extensor plantar response. Vision and hearing were normal and cranial nerves were intact; fundoscopy was normal. Examination of other systems was unremarkable. Hematological profile, renal function, liver function, serum electrolytes, ECG and cerebrospinal fluid examination were normal. An X-ray of the para-nasal air sinuses was normal. EEG showed generalized epileptiform discharged. MRI of brain revealed hemiatrophy of left cerebral hemisphere, dilatation of the left lateral ventricle. By these findings diagnosis of Dyke-Davidoff-Masson syndrome was confirmed. Patient was put on anti-epileptic drugs but despite this, seizures could not be controlled. The dose of anti-epileptic drug was increased and finally seizure was controlled and the patient was on follow up.

\section{Discussion}

DDMS is a rare condition characterized clinically by varying degree of facial asymmetry, seizures, contralateral hemiparesis, mental retardation and learning disabilities with behavioral abnormalities ${ }^{5-7}$. The radiological findings include cerebral hemiatrophy, ipsilateral osseous hypertrophy and hyper-pneumatization of sinuses ${ }^{7}$. Either sex may be affected with involvement of any cerebral hemisphere. Unal et $\mathrm{al}^{8}$ in a retrospective study of 26 patients of cerebral hemiatrophy showed that it was more frequent in the males with left cerebral hemisphere involvement. Clinical features vary depending on the extent of brain injury. A detailed history, meticulous clinical examination with radiologic findings provide clue to the diagnosis.

The disease is generally classified into primary (congenital) and secondary (acquired) variety ${ }^{4,6}$. Primary variety is mainly caused due to vascular occlusions or malformations in-utero or in the neonatal period. Neonatal or gestational vascular occlusion involving the middle cerebral vascular territory, unilateral cerebral arterial circulation anomalies, coarctation of the aortic arch, mesencephalon hypoplasia and Wallerian degeneration have been propounded as some of the etiologies for the primary variety ${ }^{3-4,6,9}$. Hageman et $\mathrm{al}^{10}$ proposed the terms cerebral hemi-hypoplasia or unilateral cerebral hypoplasia for the primary cerebral atrophy owing to the fact that there is lack of cerebral development rather than atrophy. When the cerebral hemiatrophy develops in-utero or during first two years of life, it is associated with certain cranial changes like ipsilateral hypertrophy of the skull and sinuses as a compensatory change to take up the relative vacuum created by the hypoplastic cerebrum ${ }^{6,9}$.
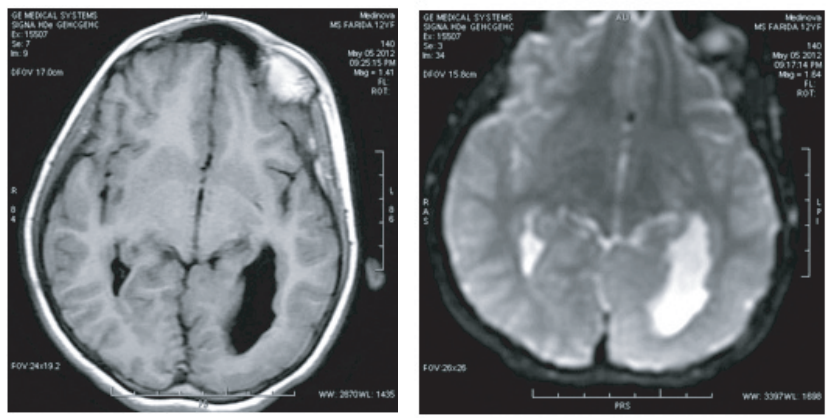

Figure 1 (T1 weighted) and Figure 2 (T2 weighted) MRI of brain revealed hemiatrophy of left cerebral hemisphere with dilatation of the left lateral ventricle

The brain reaches half the adult size during first year of life and three-fourths by the end of third year. As it enlarges, the brain presses outward on the bony tables which gradually results in general shape of the adult head. But, failure of the cerebrum to grow causes other structures to direct their growth inward, accounting for ipsilateral hyperpneumatization of the sinuses, increased width of the diploic space and elevations of the greater wing of the sphenoid and petrous ridge ${ }^{3}$. The other change in infantile type is a shift of midline structures towards the side of the disease and the sulcal prominence replacing the gliotic tissue is absent ${ }^{8}$. This feature differentiates it from cerebral hemiatrophy that occurs in later life.

Acquired variety may be due to infections, trauma, ischemia and hemorrhage. Age of presentation depends on the time of occurrence of the brain insult and often clinical features may not be evident till adolescence ${ }^{6,11,13}$. The characteristic calvarial changes may or may not be present depending upon the time of injury. Further, these insults occur after birth, after completion of sulci formation, however, mental retardation observed in this patient goes unexplained in the acquired variety. The exact mechanism of cerebral atrophy is still unclear in either type. It is hypothesized that ischemic episodes from a variety of different causes reduce the production of brain derived neurotrophic factors, which in turn lead to cerebral atrophy ${ }^{6,11-13}$. Atalar et $\mathrm{al}^{12}$ in their clinico-radiologic analysis of 19 patients concluded that, computed tomography and, in particular, magnetic resonance imaging is the procedures of choice with respect to assessment of the etiology and extent of cerebral parenchymal involvement in cerebral hemiatrophy.

The condition needs to be differentiated from basal ganglia germinoma, Sturge Weber syndrome, Linear nevus syndrome, Fishman syndrome, Silver-Russell syndrome and Rasmussen encephalitis ${ }^{6-7}$. The treatment is 
symptomatic, and includes management of convulsion, hemiparesis learning difficulties, physiotherapy and rehabilitation. Prognosis is better if hemiparesis occurs after the age of 2 years and in absence of prolonged or recurrent seizures. Children with intractable disabling and hemiplegia are the potential candidates for hemispherectomy with a success rate of $85 \%$ in carefully selected cases $^{6-7,9}$.

\section{Conclusion}

DDMS is a rare condition. Diagnasis should be made by clinical as well as radiologycal frindigy.

\section{References}

1. Dyke CG, Davidoff LM, Masson CB. Cerebral Hemiatrophy and homolateral hypertrophy of the skull and sinuses. Surgery, Gynecology \& Obstetrics 1933; 57: 588-600

2. Yerdelen D, Koç F, Koç Z. Dyke-Davidoff-Masson Syndrome. Neurosurgery Quarterly 2009; 19(1), 59-61

3. Sharma S, Goyal D, Negi A, Sood RG, Jhobta A, Surya M. Dyke Davidoff -Masson Syndrome. Indian Journal of Radiology and Imaging 2006; 16(2): 165-166

4. Pendse NA, Bapna P, Menghani V, Diwan A. Dyke - Davidoff - Masson
Syndrome (DDMS). Indian Journal of Pediatrics 2004; 71: 943

5. Shetty DS, Lakhkar BN, John JR. Dyke-Davidoff-Masson Syndrome. Neurology India 2003;51:136

6. Kumar S, Lakshmaiah V, Karthik Naidu K C. Case report: A rare cause for seizures and mental retardation - Dyke Davidoff Masson Syndrome. International Journal of Biological \& Medical Research 2011;2(4):1186 -1188 7. Narain NP, Kumar R, Narain B. Dyke - Davidoff - Masson Syndrome. Indian Pediatrics. 2008; 45: 927-928

8. Unal O, Tombul T, Cirak B, Anlar O, Incesu L, Kayan M. Left hemisphere and male sex dominance of cerebral hemiatrophy (DykeDavidoff-Masson Syndrome). Clinical Imaging 2004; 28(3):163-5

9. Goyal J, Shah V, Rao S, Jindal N. Dyke Davidoff Masson syndrome in Children. The Internet Journal of Pediatrics and Neonatology. 2009; 10(2): 101-107

10. Hageman G, Gooskens RHJM, Willemse J. A cerebral cause of arthrogryposis: Unilateral cerebral hypoplasia. Clinical Neurology and Neurosurgery 1985; 87: 119-119-122

11. Lee JH, Lee ZI, Kim HK, Kwon SH. A case of Dyke - Davidoff - Masson syndrome in Korea. Korean Journal of Pediatrics 2006; 49 (2): 208-211

12. Atalar MH, Icagasioglu D, Tas F. Cerebral hemiatrophy (DykeDavidoff-Masson syndrome) in childhood: clinic-radiological analysis of 19 cases. Pediatrics International 2007;49(1):70-7

13. Lin F Y, Lai L S. Dyke-Davidoff-Masson Syndrome with Crossed Cerebellar Atrophy. Acta Neurologica Taiwanica. 2010; 19(2):148-149 